\title{
DESVELANDO OS FATORES PSICOMOTORES PRESENTES NOS OBJETIVOS DA EDUCAÇÃO FÍSICA ESCOLAR “PCN”
}

Tiago da Silva Paiva, Janaína Pereira Duarte Bezerra.

Universidade do Oeste Paulista - UNOESTE, Presidente Prudente, SP. E_mail: janainapereira@unoeste.br, tiagoiepe@hotmail.com.

\section{RESUMO}

Partindo do pressuposto de que a psicomotricidade é uma ciência completa, que contempla aspectos cognitivos, afetivos, motores, sociais e emocionais indispensáveis para a formação do indivíduo, o presente trabalho teve como objetivo revelar quais fatores psicomotores estão presentes no documento PCN (Parâmetros Curriculares Nacionais) da disciplina Educação Física para o ensino fundamental e médio. Tal documento tem a função de orientar a realização de práticas pedagógicas através de normativas legais para os segmentos citados. Então, foi realizado um levantamento de caráter bibliográfico que possibilitou analisar o documento em questão considerando a importância dos fatores psicomotores para o desenvolvimento dos alunos, fazendo uma reflexão sobre o trabalho do docente e uma consideração sobre como o professor deve conduzir suas práticas a fim de inserir tais fatores psicomotores em suas aulas, adequando o processo de ensino e aprendizagem à condição psicomotricista. Constatamos que o fator psicomotor contido nos objetivos do Ensino Fundamental é o esquema corporal e no Ensino Médio também o esquema corporal e a tonicidade. É possível afirmar que os PCNs trazem pequena indicação de trabalho a partir dos referidos fatores, o que a nosso ver inviabiliza a compreensão do conceito de psicomotricidade, variações desse conceito e sua presença valiosa, o que culmina em uma condição muitas vezes desapercebida no ambiente escolar. Consideramos que a psicomotricidade deve ser valorizada elevando assim o papel do docente como mediador e construtor de indivíduos autônomos e críticos, basicamente transformadores sociais, sendo a ponte entre o processo de desenvolvimento, ensino e aprendizagem.

PALAVRAS-CHAVE: Fatores Psicomotores. Educação. Educação Física. Parâmetros Curriculares Nacionais.

\section{UNVEILING THE FACTORS PSYCHOMOTOR PRESENT IN PHYSICAL EDUCATION GOALS SCHOOL "PCN"}

\begin{abstract}
Based on the assumption that psychomotricity is a complete science, which contemplates cognitive, affective, motor, social and emotional aspects indispensable for the formation of the individual, the present work had as objective to reveal which psychomotor factors are present in the document National Curricular Parameters ) Of the discipline Physical Education for primary and secondary education. This document has the function of guiding the realization of pedagogical practices through legal regulations for the mentioned segments. Then, a bibliographical survey was carried out that made it possible to analyze the document in question, considering the importance of the psychomotor factors for the development of the students, reflecting on the work of the teacher and a consideration about how the teacher should conduct his practices in order to Insert such psychomotor factors in their classes, adapting the process of teaching and learning to the psychomotricist condition. We found that the psychomotor factor contained in the goals of Elementary School is the corporal scheme and in High School also the corporal scheme and the tonicity. It is possible to affirm that the PCNs present a small indication of work from the mentioned factors, which in our view makes it impossible to understand the concept of psychomotricity, variations of this concept and its valuable presence, which culminates in a condition often unnoticed in the school environment. We consider that the psychomotricity should be valued thus raising the role of the teacher as mediator and constructor of autonomous and critical individuals, basically social transformers, being the bridge between the process of development, teaching and learning.
\end{abstract}

KEYWORDS: Psychomotor Factors. Education. PE. National Curricular Parameters. 


\section{INTRODUÇÃO}

O presente trabalho buscou apontar os fatores psicomotores ${ }^{1}$ presentes nos objetivos da disciplina Educação Física para o ensino fundamental e médio de acordo com o documento orientador PCN (Parâmetros Curriculares Nacionais).

Quando falamos de objetivo pedagógico, temos que elencar práticas que viabilizam a obtenção deste alvo, e nessa direção é possível destacar que os fatores psicomotores tão necessários para o desenvolvimento motor, cognitivo e social de crianças e jovens, podem contribuir imensamente para alcançar as metas estabelecidas através dos objetivos da disciplina elencados pelo PCN para orientar o trabalho do docente em suas aulas.

É importante evidenciar que necessitamos de prerrogativas legais prédeterminadas para sustentar a base formal perante os desenvolvimentos, ou seja, as aulas apresentadas devem conter metas pedagógicas específicas para assinalar como será o trabalho durante $\mathrm{o}$ ano letivo, quais as evoluções, os métodos trabalhados, formas de avaliação e principalmente os objetivos daquele procedimento em andamento.

Os Parâmetros Curriculares Nacionais (PCN) é uma forma de regulamentação das práticas pedagógicas, que englobam vários aspectos desde a justificação da sua necessidade, bem como os objetivos, formas de avaliação e orientações em geral para o professor em cada disciplina, devemos ressaltar que o PCN se trata de uma política pública que viabiliza a prática educativa.

Freire (2001, p.21) faz uma reflexão sobre a educação e a importância/intervenção das políticas públicas na mesma: "Me parece fundamental, neste exercício, deixar claro, desde o início, que não pode existir uma prática educativa neutra, descomprometida, apolítica".

Com base em tais preceitos justificamos que tal estudo é necessário, pois uma boa prática pedagógica deve estar fundamentada em princípios técnicos, e os fatores psicomotores se aliam ao movimento corporal e tem grande valia

\footnotetext{
${ }^{1}$ Os fatores psicomotores podem ser entendidos como as bases da psicomotricidade, são eixos determinados que estão contidos nas ações do indivíduo sejam elas motoras, cognitivas e sociais e auxiliam no processo de ensino e aprendizagem sendo eles tonicidade, equilíbrio, lateralidade, noção corporal, estruturação espaço temporal, praxia fina e praxia global.
}

no processo de aprendizagem, pois segundo Le Boulch (1987),

O objetivo central da
educação pelo
movimento é contribuir
ao desenvolvimento
psicomotor da criança,
de quem depende, ao
mesmo tempo, a
evolução de sua
personalidade e o
sucesso escolar (LE
BOULCH, 1987, p.15).

Assim com base na identificação dos fatores psicomotores podemos auxiliar o trabalho do docente, formalizando uma reflexão do mesmo, para encaixar estes preceitos em suas aulas, também disponibilizaremos um debate sobre o tema psicomotor tão importante, mas que às vezes passa despercebido na formalização de um plano de ensino.

Portanto como comprova Le Boulch (1987 p.26) "[...] menosprezar a influência de um bom desenvolvimento psicomotor, seria limitar a importância da educação do corpo e recair em uma atitude intelectualista". Temos assim que levar a discussão da importância destes fatores para as aulas de educação física, bem como a inserção dos mesmos de forma prática nas aulas, relacionando também como deve ser a condução do docente destinado a realizar o trabalho.

0 presente trabalho vai se basear na literatura disponível, fazendo, uma revisão dos conteúdos dispostos para apontar os fatores psicomotores contidos nos objetivos da Educação Física escolar nos ensinos fundamental e médio conforme estipulado através dos "Parâmetros Curriculares Nacionais" (PCN), que são essenciais no processo de aprendizagem como aponta Alves (2008):

Durante o processo de
aprendizagem, os
elementos básicos da
Psicomotricidade são
utilizados com frequência.
O desenvolvimento do
Esquema Corporal,
Lateralidade, Estruturação
Espacial, Estruturação
Temporal e Pré Escrita são
fundamentais na
aprendizagem; um
problema em um destes


elementos irá prejudicar uma boa aprendizagem (ALVES, 2008, p.128).

Para esclarecer a necessidade da inserção dos fatores psicomotores nas aulas precisamos ressaltar a contribuição para o desenvolvimento em diversas áreas da criança, elencando trabalhos em grupos de forma cooperativa como aborda Le Boulch (1987):

Durante o período escolar, seria possível, apoiando-se nas atividades de expressão espontâneas realizadas em grupo, despistar entraves como a inibição, a insegurança, as dificuldades de concentração, os atrasos de linguagem (LE BOULCH, 1987, p.29).

A psicomotricidade pode ser entendida como uma ciência extremamente ampla, pois a mesma vai se relacionar com diversos aspectos da formação do indivíduo, estas bases somadas vão intervir na construção do ser como um todo, através do aperfeiçoamento dos fatores psicomotores. Assim podemos compreender a psicomotricidade como um meio de formação completo do indivíduo, que necessita da mediação do professor para sua ação efetiva na formação intelectual, motora e afetiva de crianças e jovens.

Contudo demostraremos a importância de tais fatores no desenvolvimento geral dos indivíduos na fase escolar dos ensinos fundamental e médio, fazendo uma orientação ao docente, contribuindo na aplicação prática de todos estes conceitos em suas aulas.

\section{FATORES PSICOMOTORES}

Para elencar os fatores psicomotores e posteriormente refletir sobre a importância dos mesmos, necessitamos de um maior entendimento sobre o que se refere o vasto tema da psicomotricidade. Resumir uma definição para um tema tão grande levaria a um estreitamento das diversas contribuições para o ensino e aprendizagem que a psicomotricidade tem a oferecer Alves (2008, p. 127) dá um exemplo do quanto está presente a psicomotricidade na vida e nos gestos da criança quando destaca que a "[...] psicomotricidade existe nos menores gestos e em todas as atividades que desenvolve a motricidade da criança, visando ao conhecimento e ao domínio do próprio corpo".

Levando em conta que a psicomotricidade está presente em todas as atividades que desenvolve a motricidade, podemos dizer que a mesma vai interagir com os diferentes ambientes no qual o indivíduo se encontra e em diversas áreas não só motoras, mas também cognitivas e sociais Alves (2008) reafirma isto dizendo que:

A psicomotricidade serve como ferramenta para todas as áreas de estudo voltadas para organização afetiva, motora, social e intelectual do indivíduo acreditando que homem é um ser ativo capaz de se conhecer cada vez mais e de adaptar as diferentes situações e ambientes (ALVES, 2008, p.137).

Como vimos a psicomotricidade está presente em todas as áreas de desenvolvimento da criança, e contribui para o processo de aprendizagem a partir de uma soma de aspectos motores, cognitivos e sociais. Os fatores psicomotores estão inseridos nas diversas formas de expressão da criança fazendo suas contribuições para o desenvolvimento da mesma e sendo os pilares da psicomotricidade.

Fonseca (1995) indica que os fatores psicomotores são tonicidade, equilíbrio, lateralidade, noção corporal, estruturação espaço temporal, praxia fina e praxia global. Visto quais são os fatores psicomotores o professor deve utilizar suas práticas como instrumento para a inserção destes e assim enriquecer o processo de ensino aprendizagem.

Todavia, devemos como profissionais entender cada fator psicomotor no seu íntimo e mesmo que de forma sútil programar as nossas práticas através de jogos, por exemplo, pois os indivíduos vão desenvolver e/ou aperfeiçoar suas técnicas.

Referente a isso, Alves (2008, p.115) nos dá uma dimensão da importância do jogo e das diversas formas de contribuição do mesmo:

O jogo integra os aspectos motores, cognitivos, afetivos e sociais e seria muito interessante todos os profissionais da área e o professor criarem 
oportunidades para que a motivem os alunos a participarem ativamente do processo de ensino e aprendizagem

(ALVES, 2008, p.115).

Outro fato que devemos citar é que dependendo da faixa etária é necessário abordar regras que devem ser respeitadas criando um conceito moral de delimitação do que se pode e o que não se pode, construindo um termo fundamental que é a responsabilidade como também observa Alves (2008, p. 134) “Através de jogos e brincadeiras que parecem passatempos, iremos preparar a criança para um aprendizado posterior, mostrando-lhes limites".

A maturação neurológica e biológica das crianças consiste da interação com o ambiente que ela se encontra, sendo assim, o desenvolvimento dos fatores psicomotores da mesma depende de ações internas e externas, que vão posteriormente interferir no processo de ensino e aprendizagem, pois os fatores psicomotores são mecanismos diretos no processo cognitivo.

Portanto, mais do que encaixar fatores psicomotores nas nossas práticas, necessitamos entendê-los para melhor uso e consequentemente desenvolver um trabalho específico para cada indivíduo que devido ao ambiente que ele foi exposto pode não ter desenvolvido determinado aspecto psicomotor efetivamente, fazendo com que nossa prática pedagógica e educativa venha a suprir tal demanda possibilitando um aprimoramento de áreas cognitivas, afetivas e sociais que foram trabalhas ou não de forma negativa ou de baixa intensidade.

\section{REFLEXOES SOBRE A PRÀTICA PEDAGÒGICA DA EDUCAÇÂO FìsICA}

A Educação Física escolar assim como as demais disciplinas regulares, possui objetivos para o trabalho formal do professor préestabelecidos através do PCN, tais metas referem-se como o docente deve inserir em suas práticas elementos que visam contribuir para o ensino e aprendizagem. Como os fatores psicomotores estão intimamente associados às funções, padrões e desenvolvimento físico, cognitivo e social, as aulas de educação física têm extrema ligação com os mesmos, pois as práticas pedagógicas da disciplina visam 0 desenvolvimento do indivíduo a partir do trabalho não só corporal. Contudo os alvos para o trabalho são divididos em ensino fundamental e médio, para o ensino fundamental temos como objetivos gerais para as aulas contido no PCN (1997, p.33):

$\begin{array}{lr}\text { - Participar } & \text { de } \\ \text { atividades } & \text { corporais, } \\ \text { estabelecendo } & \text { relações } \\ \text { equilibradas e construtivas } \\ \text { com os } & \text { outros, } \\ \text { reconhecendo } & \text { e }\end{array}$ respeitando características físicas e de desempenho de si próprio e dos outros, sem discriminar por características pessoais, física, sexuais e sociais;

- Adotar atitudes de respeito mútuo, dignidade e solidariedade em situações lúdicas e esportivas, repudiando qualquer espécie de violência;

- Conhecer, valorizar, respeitar e desfrutar da pluralidade de manifestações de cultura corporal do Brasil e do mundo, percebendo com recurso valioso para integração entre pessoas e entre diferentes grupos sócias;

- Reconhecer-se como elemento integrante do ambiente, adotando hábitos saudáveis de higiene, alimentação e atividades corporais, relacionando-os com os efeitos sobre a própria saúde e de recuperação, manutenção e melhoria da saúde coletiva;

- Solucionar

problemas de ordem corporal em diferentes contextos, regulando e dosando o esforço em um nível compatível com as possibilidades,

considerando que o aperfeiçoamento e o desenvolvimento das competências corporais decorrem de perseverança 
e regularidade e devem ocorrer de modo saudável e equilibrado

- Reconhecer

condições de trabalho que comprometam os processos de crescimento e desenvolvimento, não as aceitando para si nem para os outros, reivindicando condições de vida dignas;

- Conhecer a diversidade de padrões de saúde, beleza e estética corporal que existem nos diferentes grupos sociais, compreendendo sua inserção dentro da cultura em que são produzidos, analisando criticamente os padrões divulgados pela mídia e evitando o consumismo e o preconceito;

- Conhecer, organizar e transferir no espaço de forma autônoma, bem como reivindicar locais adequados para promover atividades corporais do lazer, reconhecendo-as como uma necessidade básica do ser humano e um direito do cidadão.

E para o ensino médio delimitado através do PCN (1997, p.41-42) são:

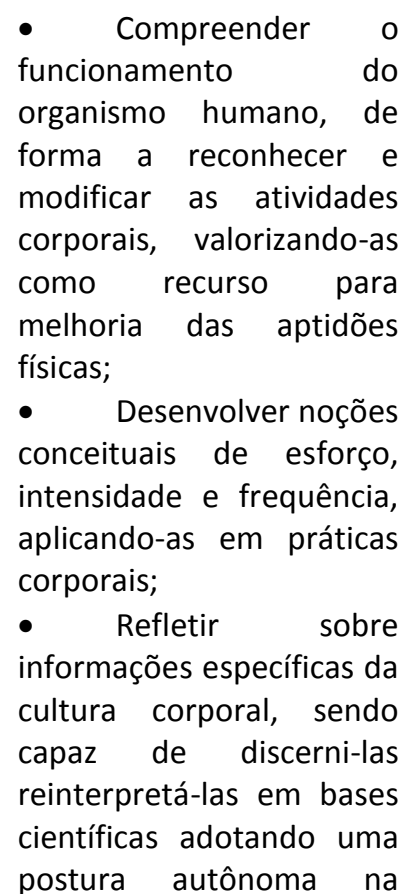

seleção de atividades e procedimentos de manutenção ou aquisição da saúde;

- Assumir uma postura ativa na prática de atividade físicas, e consciente da importância delas na vida do cidadão;

- Compreender as diferentes manifestações da cultura corporal, reconhecendo e valorizando as diferenças de desempenho, linguagem e expressão;

- Participar de atividades em grandes e pequenos grupos, compreendendo as diferenças individuais e procurando colaborar para que o grupo possa atingir seus objetivos a que se propôs;

- Reconhecer na consciência e nas práticas específicas, maneiras eficazes de crescimento coletivo, refletindo e adotando uma postura democrática sobre os diferentes pontos de vistas postos em debate;

- Interessar pelo surgimento das múltiplas variações da atividade física enquanto objeto de pesquisa, área de grande interesse social e mercado de trabalho promissor;

- Demonstrar

autonomia na elaboração das atividades corporais, assim como capacidade para discutir e modificar regras, reunindo elementos de várias manifestações de movimento e estabelecendo uma melhor utilização dos conhecimentos adquiridos sobre a cultura corporal.

Observamos acima os objetivos gerais para a educação física escolar nos ensinos fundamental e médio, através disso podemos ter 
uma visão do que se refere à presença dos fatores psicomotores.

Identificamos que no ensino fundamental a presença do esquema corporal no que diz respeito a participar de atividades corporais, solucionar problemas de ordem corporal bem como o aperfeiçoamento de competências corporais. No fator cognição podemos elencar a necessidade de conhecer, organizar e transferir tarefas no espaço de forma autônoma, relacionando a estruturação espaço temporal respectivamente, no que se trata a interação social destacamos o respeito mútuo em condições diferentes a do indivíduo seja ela física, pessoal ou sexual, sendo ainda necessário a consciência do estabelecimento de regras e reivindicações de benefícios à comunidade, pois a comunidade é uma extensão da escola que anseia pelo conhecimento dos alunos para seu aprimoramento, caracterizando um nítido processo de interação social.

No ensino médio podemos destacar também fatores ligados ao esquema corporal, como o conhecimento do funcionamento do organismo. A tonicidade aparece no aspecto de ações de intensidade e frequência em que a uso da força muscular.

No âmbito social temos a participação de grandes e pequenos grupos para obtenção de objetivos estabelecidos nas aulas pelo professor, bem como o crescimento coletivo, tudo isso vai contribuir, somado aos outros fatores para a formação de um ser autônomo que manifestará um papel importante com todo seu meio. Ressaltamos que embora a cultura popular ache que a Educação Física Escolar está somente ligada a prática física tais objetivos acima tem caráter revelador da disciplina com os outros meios por ela exploramos como destaca o PCN (1997):

Embora numa aula de
educação física os
aspectos corporais sejam
mais evidentes, mais
facilmente observáveis, e
a aprendizagem esteja
vinculada á experiência
prática, o aluno precisa ser
considerado como um
todo no qual os aspectos
cognitivos, afetivos e
corporais estão inter-
relacionados em todas as
situações PCN (1997,
p.27).

A importância dos fatores psicomotores se dá na amplitude que os mesmos oferecem, pois não só se relacionam com a prática motora, mas também social e cognitiva podendo assim dizer que a psicomotricidade é completa, no que diz respeito a sua necessidade no processo de ensino e aprendizagem. O professor ganha uma imensa responsabilidade, pois faz a ponte do ensino, escola e sociedade tendo caráter de agente transformador cultural e sociológico como expressado por Ghiraldelli Junior (2007),

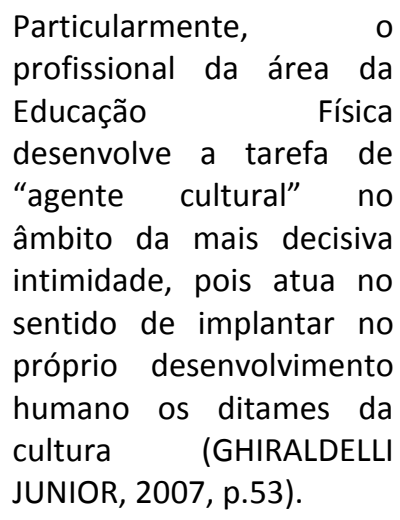

A necessidade de atualização de informação do professor deve ser constante, pois poderá melhorar suas práticas com a interação de outras disciplinas, por exemplo, usando aspectos matemáticos embutidos em suas práticas ativando a cognição e contribuindo para o físico e indiretamente com outra disciplina como expõe Darido (2008):

Propomos, portanto, que
o professor aprenda a
refletir sobre sua prática
profissional, não apenas
em relação as suas aulas,
mas que reflita sobre o
contexto de sua escola e
de sua profissão,
valorizando-as igualmente
e trocando informações
advindas dessas reflexões
com outros professores,
tanto os de Educação
Física, quanto de outras
disciplinas (DARIDO, 2008,
p.106).

Tal interação da Educação Física é necessária, pois faz o professor ter uma crítica sobre suas aulas, ouvir conceitos novos de outros professores de disciplinas diferentes, promovendo um debate enriquecedor para o ambiente escolar transformando suas aulas como ressalta Freire (1996, p.18), “[...] por isso é que, 
na formação permanente dos professores, o momento fundamental é o dá reflexão crítica sobre a prática".

Ao longo da vida escolar a interação da Educação Física com as demais áreas do conhecimento é importante, pois auxilia diretamente na construção do estudante como cidadão ativo na sociedade, e este processo se dá durante toda a vida escolar assim como aborda Mattos e Neira (2008),

Para tanto é necessário que as decisões assumidas pelo professor auxiliem os alunos a desenvolver atitudes e procedimentos adequados a uma postura autônoma de estudante, que só será efetivamente alcançada através de investimentos

sistemáticos ao longo de toda a escolaridade Mattos e Neira (2008, p.32):

O professor de Educação Física deve usar atividades em suas aulas que levem à cooperação, o coletivo e que trabalhem conceitos cognitivos, físicos e sociais, usar como exemplo a estruturação temporal com tonicidade, tal interação destes fatores psicomotores vai influenciar diretamente na aprendizagem em outras disciplinas, dando um aspecto transformador as aulas de Educação Física.

Portanto de uma maneira clara o uso da Educação Física possibilita a mesma a ser instrumento de ensino e aprendizagem a diversas áreas do conhecimento, ganhando papel transformador, formador e o mais importante crítico, visando à construção de um ser autônomo e ativo na sociedade. Com base na psicomotricidade podemos elevar nossas aulas em nível alto de aprendizagem, pois os fatores psicomotores estão estabelecidos desde os objetivos técnicos da Educação Física, até em suas pequenas ações em quadra ou na sala de aula.

\section{CONSIDERAÇÕES FINAIS}

Visto que a psicomotricidade interage com diferentes ambientes em que o indivíduo se localiza, nas formas de expressões que o mesmo usa para se adaptar, integrar e socializar-se com os demais. Podemos assim dizer que os fatores psicomotores estão presentes em todo o trabalho da Educação Física escolar. Ao analisar os objetivos para o ensino fundamental e médio, constatamos que os fatores psicomotores estão espalhados em diferentes ações, funções, e às vezes possuem intervenções diretas mais evidentes nas ações do planejamento, como o uso da tonicidade para realizar ações motoras, ou estão indiretamente contidos dentro de uma ação que pode ser simples, mas vai incluir um ganho psicomotor ao indivíduo que a realiza, no trabalho da integração social, por exemplo, quando divididos os alunos precisam conversar e organizar ações para resolver um problema na atividade, fazendo uma construção de um indivíduo social ativo fora da escola.

Determinamos que os fatores psicomotores nas aulas de Educação Física são importantes, pois, a psicomotricidade é um ramo completo e extenso que integra ações motoras, cognitivas e sociais contidos em fatores específicos (tonicidade, equilíbrio, lateralidade, noção corporal, estruturação espaço temporal, praxia fina e praxia global). Tais fatores proporcionam uma construção perfeita de um indivíduo, e que através disto o prepara para ações a serem realizadas fora de sua vida escolar, sendo elas cognitivas, no sentido de um indivíduo pensante, capaz de resolver e organizar ações, ou até mesmo motor, no caso do uso de suas habilidades para auxilio em sua vida prática, seja ela no trabalho, no lazer ou até mesmo em sua casa, construindo também uma saúde corporal.

As práticas pedagógicas visam à construção de um ser ativo, autônomo e crítico como observa Darido (2008):

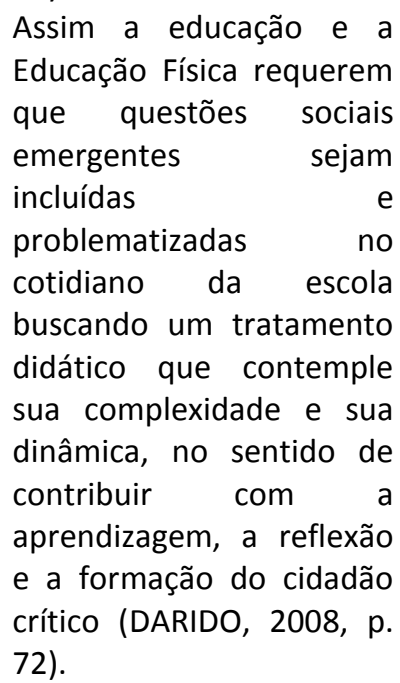

Contudo para que isso seja possível, inclusive para que a psicomotricidade tenha papel amplo na transformação do indivíduo, é 
necessário um instrumento essencial, o professor. O docente tem papel chave e faz a ponte entre ensino e aprendizagem, no caso da inserção de todos os fatores psicomotores nas aulas práticas, sejam elas nas quadras ou salas de aula o professor é viabilizador desta prática e deve adicionar os conceitos desde seu planejamento pedagógico, e estar atento às necessidades dos alunos e as suas evoluções motoras, cognitivas e sociais enfrentando todas as dificuldades apresentadas em todo o ambiente escolar, com mais ênfase no ensino público como destaca LIBÂNEO et al. (2009, p. 116), " [...] no âmbito da educação escolar, o ensino público de qualidade para todos é uma necessidade e um desafio fundamental".

Por isso é necessário uma avaliação constante, uma capacitação e especialização dos docentes para que os mesmo saibam, além de identificar os fatores psicomotores em menor desenvolvimento nos alunos, mas também lapidar estes conceitos, alguns necessitam de maior atenção, outros de maior motivação e todos precisam de uma orientação, um cuidado, pois acima de todos os meios técnicos pedagógicos, a psicomotricidade é uma ciência humana e carece de atenção especial, pois cada indivíduo é único e interage e reage ao meio de forma diferente do outro, sendo passível de compreensão do docente para uma boa atuação técnica na prática.

\section{REFERÊNCIAS}

ALVES, Fátima. Psicomotricidade: corpo, ação e emoção. 4.ed. Rio de Janeiro: Walk, 2008.
DARIDO, Cristina Suraya. Educação física na escola: questões e reflexões. Rio de Janeiro: Guanabara Koogan, 2008.

FONSECA, V. Manual de observação psicomotora: significação psiconeurológica dos fatores psicomotores. Porto Alegre: Artes Médicas, 1995.

FREIRE, Paulo. Pedagogia da autonomia, saberes sobre á prática educativa. São Paulo: Paz e Terra, 1996.

Cortez, 2001.

Paulo. Política e educação. São Paulo: GHIRALDELLI JUNIOR, Paulo. Educação física progressista. São Paulo: Edições Loyola, 2007.

LE BOULCH, Jean. Educação psicomotora: psicocinética na idade escolar. Porto Alegre: [s.n.], 1987.

MATTOS, Mauro Guedes de; Neira, Marcos Garcia. Educação física na adolescência. São Paulo: Phorte, 2008.

Recebido para publicação em: 24/04/2016

Revisado em: 27/04/2016

Aceito em: 30/04/2016 